\title{
Panel recommends health care innovation fund to be administered by new agency
}

$\mathrm{T}$ he federal government should invest in a new, arms-length health care innovation fund with a budget that would grow to $\$ 1$ billion a year by 2020 — that would finance high-impact initiatives, break down structural barriers and accelerate promising health care innovations, recommends the Advisory Panel on Healthcare Innovation in its new report, Unleashing Innovation: Excellent Healthcare for Canada.

A new organization called the Healthcare Innovation Agency of Canada would administer the fund. The agency would consolidate the activities of three existing agencies, from which it would draw its staff: the Canadian Patient Safety Institute, Canada Health Infoway and the Canadian Foundation for Healthcare Improvement.

The agency and the fund would be designed to help create a new model for federal engagement in the health care system - one that requires shared commitment from the provinces, territories and all stakeholders, including patients, the report makes clear. It calls for "bold federal action and prudent investment," as well as the political will required to change the course of the Canadian health care system.

"Time after time, ideas surface in Canadian health care, because of all the talent in the system, that could lead to improvements," Dr. David Naylor, the panel's chair, told CMAJ in an interview. "And, somehow or other the changes aren't made that would improve the quality of working life for people in the system ... but would also improve the quality of care and outcomes and value we can provide."

Many stakeholders suggested the idea of a fund and an agency to administer it to ensure that innovation is applied on the front lines of care, Naylor, the former president of the University of Toronto, told CMAJ. Currently, the health care system lacks the capacity to explore different incentive systems and conversations with regulators to allow all health care professionals to work in their full scopes of practice, he said.

"This is about having an 'Innovation Switzerland' with a modest bank account," he said. Even at $\$ 1$ billion a year, that is "less than one half of one percent of the federal budget," Naylor pointed out.

The panel's sweeping recommendations include:

- creating a new refundable health tax credit for Canadians;

- creating a First Nations Health Quality Council;

- creating a national strategy to implement "precision medicine" into frontline care, involving the use of biomarkers to tailor individual treatment and medicine;

- creating a patient and family-centred care strategy;

- creating strategies to ensure integrated health delivery addresses the social determinants of health;

- identifying best practices in shared professional care;

- supporting the Choosing Wisely Canada initiative; and

- creating new payment models that would involve fees for "bundled" services to promote prevention, continuity of care and provision of services, rather than a fee-for-service model.

"We have this extraordinary medical talent in the country, and yet we do not find many wants to incent physicians to be engaged in stewarding health care resources and building high-performance teams," Naylor said.

The recommendations reflect the panel members' evident frustration with Canada's inability to respond to the stresses that are damaging the existing health care system.

"Medicare is aging badly," the report's executive summary concludes. "The Panel has been left in no doubt that a major renovation of the system is overdue, and is chagrined and puzzled by the inability of Canadian governments federal, provincial, and territorial — to join forces and take concerted action on recommendations that have been made by many previous commissions, reviews, panels, and experts."

One of the biggest barriers to progress in reforming Canada's health care system is the country's inability to "scale up" promising innovations that may exist at local or regional levels, the report says.

"Pockets of extraordinary creativity and innovation dot the Canadian healthcare landscape," the panel's authors wrote. "Local, regional and even provincial programs worthy of emulation have simply not been scaled-up across the nation."

That barrier is exemplified by the lack of any dedicated funding that would drive systemic innovation, as well as by our "fragmented" system, with its variety of budgets and accountability structures. The panel was also highly critical of the "slow deployment and incomplete utilization" of modern information technology — such as electronic patient records to which patients also have easy access.

The innovation panel's mandate was to recommend five ways Ottawa could support innovative improvements in patient care and to the health care system. There were two caveats: the recommendations were not to raise the overall cost to taxpayers and the panel had to respect the provincial/territorial jurisdiction for health.

Instead of "five quick fixes or big trends," a few made-in-Canada solutions and "some policy palliatives," which some stakeholders had expected, the group came up with five overarching themes and a series of recommendations within each. That led to a "wide-angle view of healthcare innovation" - perhaps a wider angle than the federal government intended, just three months before the federal election.

"We do not have a reaction from the government yet," said Naylor, who 
expects it will take time to study the detailed report. "I have to anticipate that this is a challenging timing because it arrives as we are already in the midst of electioneering and any of these reports can quickly become a political football."

The report does not, however, direct all its criticism at the federal government. The report also notes the inability of the provinces and territories to act on expanding local and regional initiatives and to cooperate on a pan-Canadian drug procurement strategy.

The panel members also went out of their way to praise senior officials in Health Canada and federal Health Minister Rona Ambrose for respecting the group's independence. Asked about whether the report was delayed from its original release date because of political interference from the Prime Minister's
Office or the Privy Council Office, Naylor was circumspect.

"I have no comment on any interference. I can tell you the content of the report is exactly what the panel wrote and we are delighted to have it out only a few days after we were ready to put it out," Naylor said. — Laura Eggertson, Ottawa, Ont.

CMAJ 2015. DOI:10.1503/cmaj.109-5117 